\title{
QoS Performance Analysis of Video Conferencing Over Wimax using different Modulation Schemes
}

\author{
Komaldeep Kaur \\ Student in ECE Department \\ GNDU RC, Jalandhar
}

\author{
Vinit Grewal, PhD \\ Professor in CSE Department \\ GNDU RC, Jalandhar
}

\begin{abstract}
Streaming media such as video conferencing and online multimedia gaming usage on mobile data has been increased. In this paper, analysis of video conferencing over WiMAX network is discussed. For secure video transmission over WiMAX, analysis of PHY(Physical) and MAC layer for different modulation schemes is presented using OPNET modeler 14.5.
\end{abstract}

\section{Keywords}

MAC, PHY, QoS, Video Conferencing, WiMAX

\section{INTRODUCTION}

Mobile wireless communication, because of its adaptability and flexibility has now become a necessity. A user not only wants the basic voice functionality of mobile wireless devices, but also multimedia and data communication applications. Over the years, with the improvement of technology, the bandwidth over the wireless network has been increasing, at a measured pace. Over the past few decades, different modulation schemes have been developed to increase the data rate supported in wireless networks thus supporting a higher data rate. Technologies like Wi-MAX and other 3G technologies can theoretically support up to $74 \mathrm{Mbps}$ per channel [1].

WiMAX(Wireless Interoperability for Microwave Access) is one of the developing technology in recent times with a proposal of bringing the usage of broadband till last mile[2]. WiMAX belongs to IEEE802.16 standard and guarantee the broadband wireless internet access at very high data rate. WiMAX is the wireless standard which covers area up to 50 $\mathrm{km}$ and provide 30 to $40 \mathrm{mbps}$ data rate. It is the replacement for DSL (Digital Subscriber Line) and cables. WiMAX can be used for various applications like rural area broadband services, wireless backhaul, Wi-Fi hotspot, voice over Internet Protocol(VoIP), video conferencing. Some salient features of WiMAX are Fixed WiMAX (802.16-2004) and Mobile WiMAX (802.16-2005) are two versions of WiMAX which allows mobility without losing connections. The range and bandwidth of WiMAX makes it suitable for following applications [2]:

- WiMAX uses adaptive modulation and coding, multiuser diversity and spatial multiplexing. These techniques allow improving the overall capacity of the system.

- WiMAX has flexible MAC layer which can accommodate different type of traffic in multimedia applications.

- WiMAX supports very high peak data rate and it can be as high as $74 \mathrm{mbps}$.
- WiMAX specifies security functions such as strong encryption and authentication

- WiMAX an all-IP-based network architecture that allows all the advantages of IP .

- Advantages of WiMAX is that it has lower deployment and maintenance cost than wired infrastructure, mobility support, high-data rates, and possible in WiMAX to use unlicensed frequency bands.

In section I of this paper, a brief QoS analysis of video conferencing in WiMAX is presented. Following the introduction, section II discuss about video conferencing in WiMAX network, showing different level of services which provides WiMAX QoS and WiMAX architecture. In section III, system module and various system parameters used for analysis of video conferencing in OPNET are discussed using OPNET modeler 14.5. Section V, discuss simulation results and analysis. Finally section VI, conclude the paper.

\section{VIDEO CONFERENCING IN WiMAX}

Internet users are getting more interested in broadband applications that requires guarantee in terms of throughput and packet delay for better performance. Multimedia application such as Voice over IP (VoIP) and Video Conferencing are the two demanding applications in the recent times. Voice and video applications are noise and delay sensitive which require higher bandwidth. Therefore quality of service (QoS) has become important parameter for supporting such applications. The Worldwide Interoperability for Microwave Access (WiMAX) is a popular wireless broadband technology having strong provision for QoS support of multimedia applications. This paper analyze the performance of video conferencing. Parameters that indicate Quality of Service such as delay, jitter, packet loss and throughput are analyzed constructing different scenarios on the basis of different modulation and coding schemes defined WiMAX system[4].

\subsection{QoS in WiMAX}

As the rapid growth of multimedia application over Internet, it is required to maintain the QoS, which is ensuring the guaranteed service through Internet. For Example, Voice and Video services are bandwidth extensive, which requires less delay to maintain the QoS. It is not always possible to maintain the quality of all requirements. Quality of service is the guarantee of the service-level performance for a data stream from a source to destination. WiMAX broadly uses 5 QoS classes which are described in Table 1. WiMAX includes QoS mechanism in the architecture of MAC layer [4, 9]. 
Table 1. WiMAX service classes

\begin{tabular}{|l|l|l|}
\hline QoS Classes & $\begin{array}{l}\text { Designation } \\
\text { Defining QoS } \\
\text { Parameters }\end{array}$ & $\begin{array}{l}\text { Application } \\
\text { Examples }\end{array}$ \\
\hline $\begin{array}{l}\text { Unsolicited grant } \\
\text { services (UGS) }\end{array}$ & $\begin{array}{l}\text { Maximum } \\
\text { sustained rate } \\
\text { Depends on delay } \\
\text { Jitter tolerance }\end{array}$ & $\begin{array}{l}\text { Voice over IP } \\
\text { (VoIP) without } \\
\text { silence } \\
\text { suppression }\end{array}$ \\
\hline $\begin{array}{l}\text { Real-time } \\
\text { Polling service } \\
\text { (rtPS) }\end{array}$ & $\begin{array}{l}\text { Minimum reserved } \\
\text { rate } \\
\text { Delay dependent } \\
\text { Traffic priority }\end{array}$ & $\begin{array}{l}\text { Streaming audio } \\
\text { and video, } \\
\text { MPEG (Motion } \\
\text { Picture Experts } \\
\text { Group) encoded }\end{array}$ \\
\hline $\begin{array}{l}\text { Non-real-time } \\
\text { (nolling service }\end{array}$ & $\begin{array}{l}\text { Minimum reserved } \\
\text { rate } \\
\text { Traffic priority }\end{array}$ & $\begin{array}{l}\text { File Transfer } \\
\text { Protocol (FTP) } \\
\text { TFTP } \\
\text { HTTP }\end{array}$ \\
\hline $\begin{array}{l}\text { Best-effort } \\
\text { service (BE) }\end{array}$ & $\begin{array}{l}\text { Maximum } \\
\text { sustained rate } \\
\text { Traffic priority }\end{array}$ & $\begin{array}{l}\text { Web browsing } \\
\text { Data transfer } \\
\text { Email }\end{array}$ \\
\hline $\begin{array}{l}\text { Extended real- } \\
\text { time } \\
\text { service } \\
\text { (ErtPS) }\end{array}$ & $\begin{array}{l}\text { Minimum reserved } \\
\text { rate } \\
\text { Maximum } \\
\text { sustained rate } \\
\text { Maximum latency } \\
\text { tolerance } \\
\text { Jitter tolerance } \\
\text { Traffic priority }\end{array}$ & $\begin{array}{l}\text { VoIP } \\
\text { silence } \\
\text { suppression and } \\
\text { activity } \\
\text { detection }\end{array}$ \\
\end{tabular}

Aforestated users are getting more interested in broadband applications that requires guarantee in terms of throughput and packet delay for better performance [10]. Broadband applications such as video conferencing whose property in WiMAX is functionally realized which consist of mainly two layers i.e. MAC and Physical layer.

MAC Covergence Sublayer
(ATM Ethernet, IP)

MAC Common Part Sublayer

(Packing Fragmentation ARQ, QoS)

MAC Privacy Sublayer

(Authentication Key Exchange Privacy (encryption))

Physical Layer

(OFDM, Ranging, Transmission and Reception)

Fig 1. WiMAX layer architecture

The WiMAX PHY layer $[2,7,11]$ is mainly consist of 3 major parts transmitter, channel and receiver. It is also based on OFDM, which is a multiuser version and allows overcoming the multipath distortion and inter-symbol interference. The scheme of choice is to enable high speed data, video conferencing and multimedia communication. The PHY layers defined in WiMAX are Wireless MAN OFDM, Wireless MAN SC, Wireless MAN OFDMA and Wireless MAN Sca.
MAC layer is part of Data link layer of OSI stack. MAC layer is subdivided into 3 layers that is MAC Convergence Sublayer (CS), MAC Common Part layer (CPS) and MAC Privacy Sublayer (PS).

MAC Convergence Sublayer(CS): It is also responsible for allowing bandwidth allocation and preserving/enabling QoS. It provides two different services i.e. ATM and packet convergence sublayer.

MAC common Part Sublayer (CPS): It manages the QoS(quality of Service) associated with the different MAC protocol data units (MPDUs). QoS guarantee become important need for next generation, to enable novel approach for broadband multimedia applications. Quality of service is the guarantee of the service-level performance for a data stream from a source to destination.

Privacy Sublayer (PS): It provides secure key exchange and encryption. It provides two different protocols, encapsulation to encrypt data across the network and authentication and Privacy Key Management (PKM) to facilitate secure distribution of the keying data from the BS to SS.

\section{MODELLING OF SYSTEM PARAMETERS OF VIDEO CONFERENCING IN WIMAX}

To measure the QoS parameters for video conferencing on WiMAX, scenario shown in the figure 2 is used.

In this paper, 3 wireless scenarios for analyzing QoS of video conferencing have been considered named QAM, 16QAM and QPSK which uses same configurations for simulation for fixed and mobile users but different modulation schemes. In the simulation in order to have fairer comparison, we have used rtPS (real time polling service) for video conferencing in WiMAX. In this scenario 4 hexagonal cells are taken and each cell has one Base Station. The BS connected to the IP backbone via ppp_adv link. The node 0 and vod_server is connected to backbone through ppp_sonet_oct1 duplex link

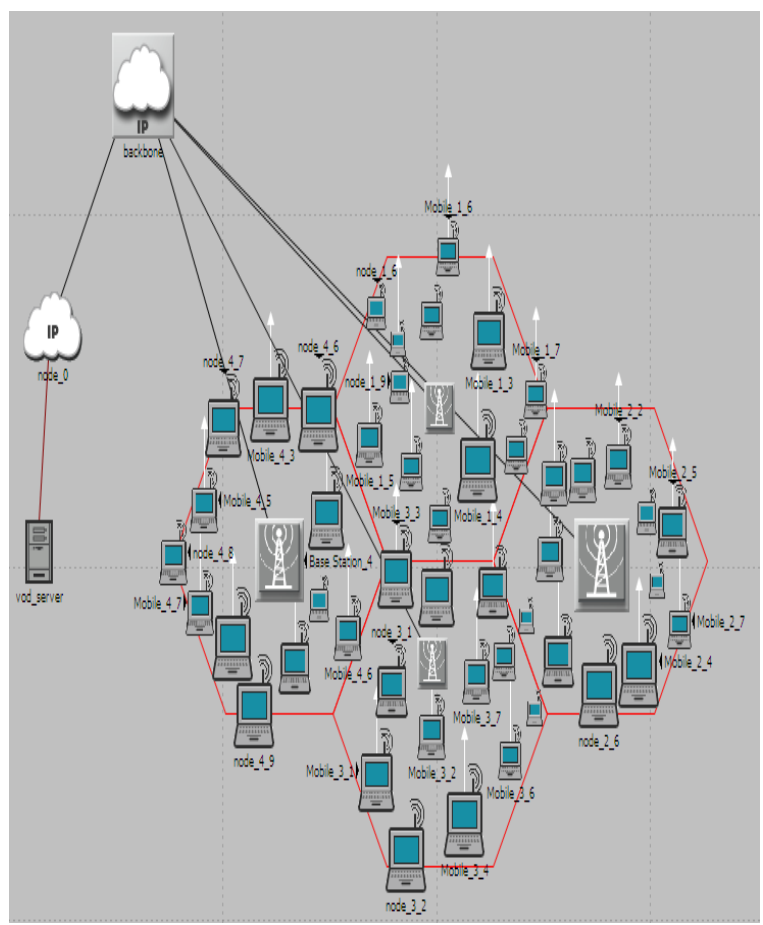

Fig 2: Video Conferencing in WiMAX Scenario 
The various performance QoS parameters used for analysis:

Table 2: Simulation parameters

\begin{tabular}{|c|c|}
\hline Parameters & Values \\
\hline PHY Layer & IEEE 802.16 \\
\hline BS transmission power & $0.5 \mathrm{~W}$ \\
\hline Base Station antenna gain & $15 \mathrm{dBi}$ \\
\hline Mobile Station antenna gain & $-1 \mathrm{dBi}$ \\
\hline Modulation schemes & QPSK3/4 \\
& 16-QAM3/4 \\
& Vehicular environment \\
\hline Pathloss parameter & $2 \mathrm{~km}$ \\
\hline Radius of cell & 28mobile, 20fixed \\
\hline $\begin{array}{c}\text { Number of fixed and mobile } \\
\text { nodes }\end{array}$ & Wireless OFDMA 20 MHz \\
\hline PHY profile & 480 \\
\hline $\begin{array}{c}\text { Simulation time(sec) } \\
\text { Efficiency mode }\end{array}$ & Mobility and Ranging \\
& \\
\hline & \\
\hline
\end{tabular}

Delay: Delay is the time of generation of packet by source to destination reception. So it is the time taken by packet to go across the network. The time can be expressed in seconds. All the delay in the network are called packet end to end delay.

Load: This represents the total load submitted to WiMAX layers by all higher layers in all WiMAX nodes of the network. It can be represented in bits/sec and packets/sec.

Throughput: Presents the amount of successful data transferred from one location to another over a specific period of time.

Packet End-to-End delay: Packet end to end delay is also known as time taken for a packet to be transferred from source to destination. End-to-end delay less $400 \mathrm{~ms}$ is considered acceptable. It is the most important parameter in video conferencing because it affects the QoS and degrades the system performance

Packet Delay Variation: In packet delay variation, variation in packet is seen which are transmitted, but not received by receiver in intended time. It can degrade the performance of system. Low paket delay variation is important.

\section{RESULTS AND ANALYSIS}

In this section, results for QoS performance of video conferencing in WiMAX network through extensive simulations are presented. All the fixed and mobile users use same configuration but different modulation and coding scheme.

Packet End to End Delay: From the given figure it is analyzed that packet end to end delay in case of QPSK is higher than other two modulation schemes. Packet end to end delay in case of 16QAM is lowest.

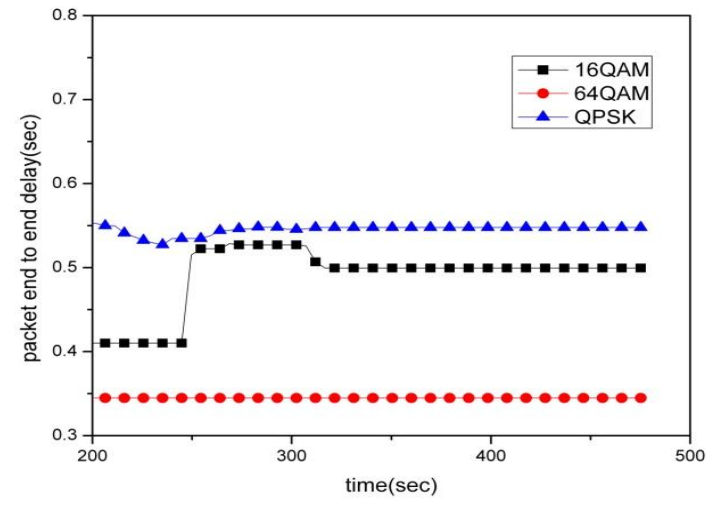

Fig 2. Packet end to end delay

Packet delay variation: It is clearly analyzed from the figure 3 that delay in case of 64QAM is less than other modulation schemes for more users whereas in QPSK delay is higher. So packet delivery time in case of 64QAM is less than other modulation schemes.

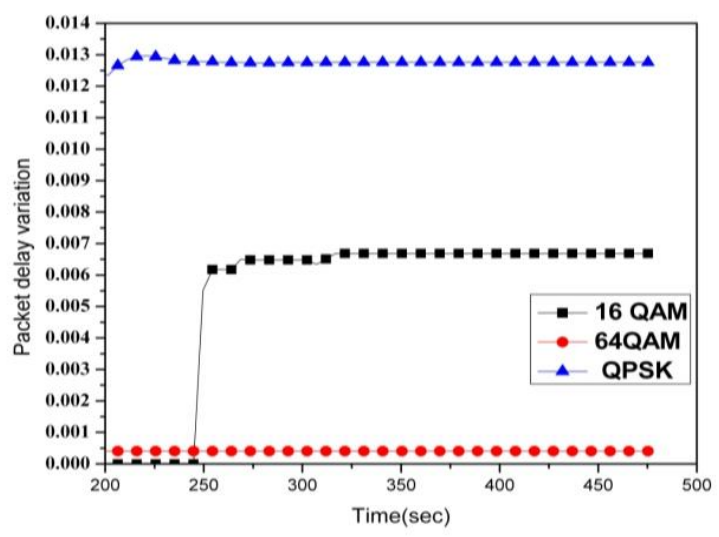

Fig 3. Packet delay variation

Traffic Received: Traffic received is the amount of data received by the mobile station. It can be measured in bits/sec and packets/sec. From the figure 4 it is clearly analyzed that QPSK modulation scheme receives more traffic than QAM modulation scheme. It is advantageous to use QPSK scheme in case when there is a need to receive more traffic.

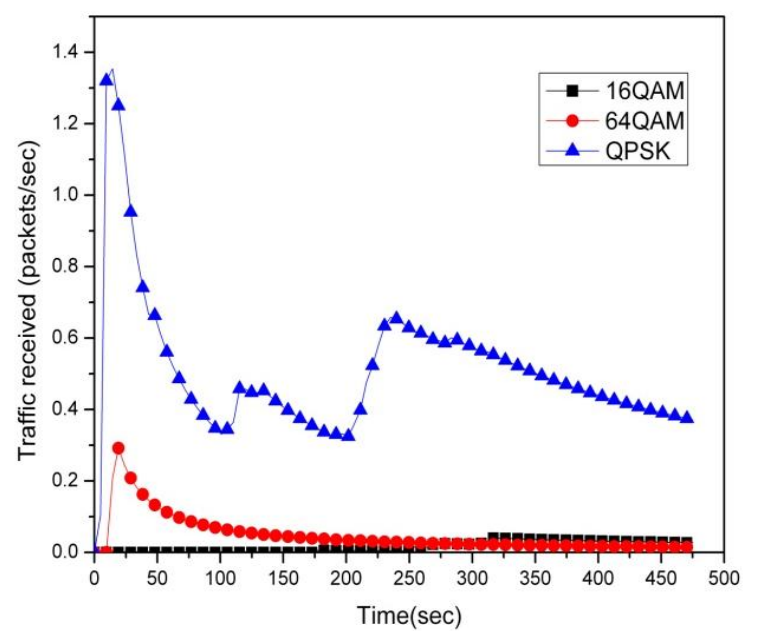

Fig 4. Traffic received (packets/sec) 
Traffic Sent: Traffic sent is the amount of data sent by base station to mobile stations. Traffic rate should be high so that even if data is lost or delayed on the way, not much loss will occur. It can be measured as bits/sec and packets/sec. From the figure it is clear that 64QAM modulation schemes performance is best followed by 16QAM and QPSK.

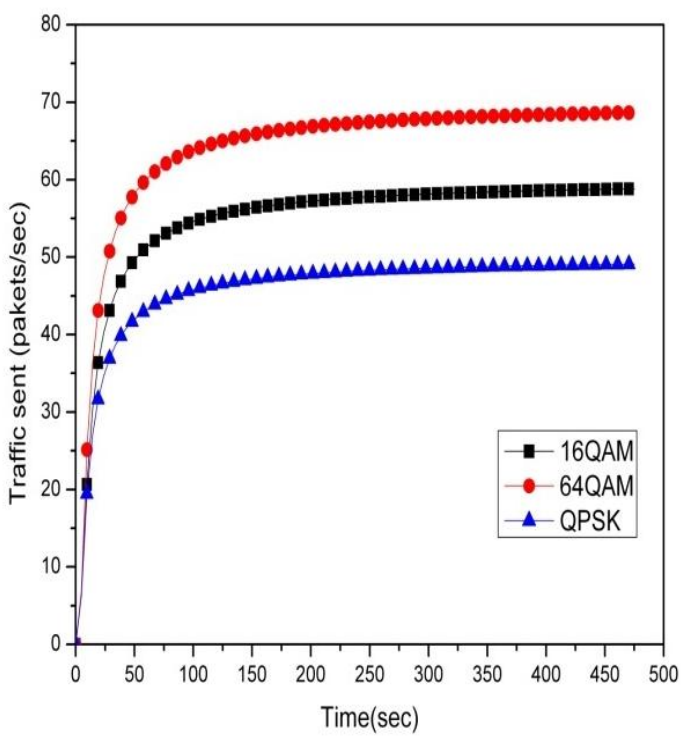

Fig 5. Traffic sent (packets/sec)

Throughput: Throughput is measured in bits/second (bps) or packet/second. From the figure we can analyze that data transferred over specific time period in case of QPSK is better than 16qam and 64QAM.

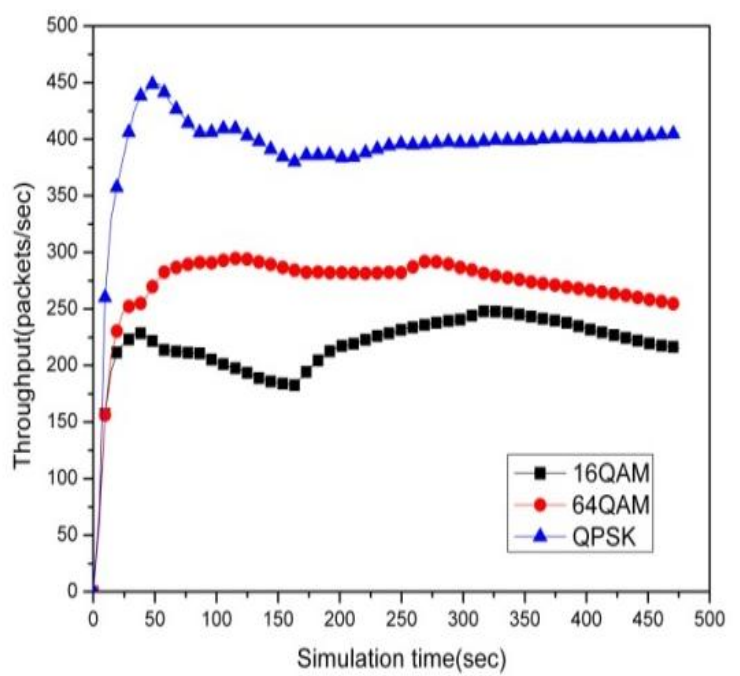

Fig 6. Throughput

Load: It is defined as the load which is applied by all higher layers to WiMAX layers. Figure 7 clearly shows that load in case of QPSK is lowest whereas in case of 64QAM is it highest..

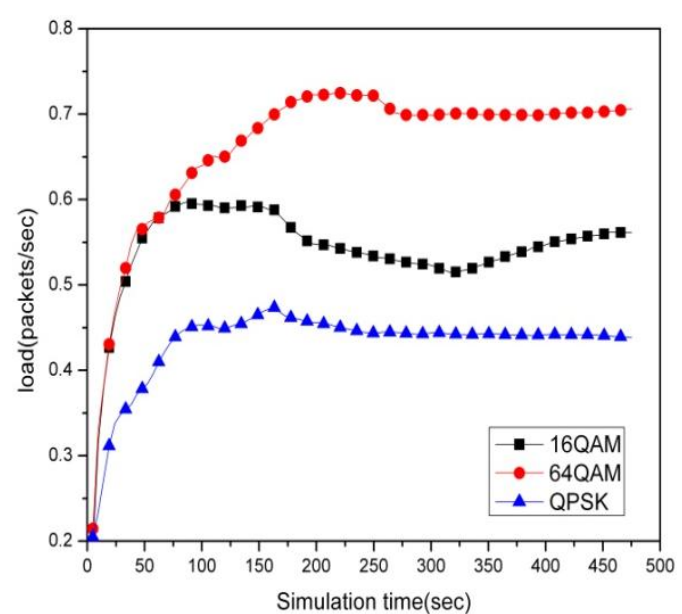

Fig 7. Load (packets/sec)

Comparative study of all the modulation schemes and their average value is shown in Table 3 and the table clearly defines the QoS performance analysis of video conferencing in WiMAX over different modulation schemes

Table 3: Measured QoS parameters for different modulation schemes

\begin{tabular}{|c|c|c|c|}
\hline $\begin{array}{c}\text { Video } \\
\text { conference } \\
\text { parameter }\end{array}$ & $\begin{array}{c}\text { QPSK3/4 } \\
\text { (average) }\end{array}$ & $\begin{array}{c}\text { 16- } \\
\text { QAM3/4 } \\
\text { (average) }\end{array}$ & $\begin{array}{c}\text { 64- } \\
\text { QAM3/4 } \\
\text { (average) }\end{array}$ \\
\hline $\begin{array}{c}\text { Packet End to } \\
\text { End Delay }\end{array}$ & 0.524968 & 0.483856 & 0.344549 \\
\hline $\begin{array}{c}\text { Traffic } \\
\text { Received(packets } \\
\text { /sec) }\end{array}$ & 0.050537 & 0.014885 & 0.047351 \\
\hline $\begin{array}{c}\text { Traffic } \\
\text { sent(packets/sec) }\end{array}$ & 48.68345 & 54.50783 & 63.70615 \\
\hline $\begin{array}{c}\text { Throughput } \\
\text { (packets/sec) }\end{array}$ & 405.175 & 215.6354 & 253.8396 \\
\hline $\begin{array}{c}\text { Packet Delay } \\
\text { Variation(sec) }\end{array}$ & 0.432382 & 0.542232 & 0.664639 \\
\hline $\begin{array}{c}\text { Load } \\
\text { (packets/sec) }\end{array}$ & 867.2542 & 908.1396 & 1073.027 \\
\hline \multicolumn{2}{|c|}{} & & \\
\hline
\end{tabular}

\section{CONCLUSION}

In this paper, the performance analysis for QoS of video conferencing over WiMAX network using OPNET modeler 14.5 is carried out with respect to different modulation schemes. To better analyze the performance service class rtPS is used, over various modulation schemes like 64QAM3/4, 16QAM3/4, QPSK3/4. Brief overview of WiMAX and video conferencing in WiMAX is described. The Performance has been evaluated for throughput, packet delay variation load, packet end to end delay and other QoS performance parameters. Comparative study of different modulation schemes for various QoS parameters is shown in tabular form. From the table it is clear that QPSK performance is better in case of traffic received, throughput and delay whereas performance of 64QAM is good in traffic sent, load and packet end to end delay. In future, QoS parameters should be improved to get minimum delay and maximum throughput over different modulation schemes with HARQ scheme. 


\section{REFERENCES}

[1] Garik Markarian,"Novel Technique For Efficient Video Distribution over WiMAX Networks",2010 IEEE International symposium".

[2] Jeffrey G. Andrews, "Fundamentals of WiMAX: Understanding Broadband Wireless Networking",(Prentice Hall Communications Engineering and Emerging Technologies Series) Prentice Hall; 2007.

[3] Farrukh Ehtisham, "Performance evaluation of secure video transmission over wimax,", International Journal of Computer Networks \& Communications (IJCNC) Vol.3, No.6, November 2011.

[4] Kamini Jaswal, "OPNET BASED SIMULATION AND INVESTIGATION OF WIMAX NETWORK USING DIFFERENT QoS", IJRET: International Journal of Research in Engineering and Technology.

[5] OPNET official website, http://www.opnet.com.
[6] Filip Zivkovic, "Quantitative Analysis of Streaming Multimedia over WiMAX and LTE Networks Using OPNET v. 16.0".

[7] Narendra Bagoria, "Simulation of Physical layerof WiMAX Network using OPNET Modeller", International Journal of P2P Network Trends and Technology(IJPTT) -Volume3Issue4-May 2013.

[8] Funmilayo Lawal (2011), "Sending Video Over WiMAX for Inter-Vehicle Communications,".

[9] Amritpal Kaur (2012), "Analysis of QoS for Video Conferencing and Voice Application in WiMAX Network"," International Conference on Recent Advances and Future Trends in Information Technology (iRAFIT2012)

[10] Tsistserov Dmitry (2010), "Segmented Video Distribution over WiMAX: Proposed approach and experimental Methodology,” IEEE

[11] Suherman, "A Novel Approach for Implementing Worldwide Interoperability for Microwave Access for Video Surveillance," Faculty of Technology, De Montfort University. 